\title{
Time-Resolved Measurements of Individual Ion Cloud Signals to Investigate Space-Charge Effects in Plasma Mass Spectrometry
}

\author{
John W. Olesik and Michael P. Dziewatkoski \\ Laboratory for Plasma Spectrochemistry, Laser Spectroscopy and Mass Spectrometry, Department of Geological \\ Sciences, The Ohio State University, Columbus, Ohio USA
}

\begin{abstract}
A new approach to directly monitor space charge induced effects due to high concentrations of efficiently ionized elements in inductively coupled plasma mass spectrometry (ICP-MS) is described. The broadening of ion clouds produced from individual, monodisperse drops of sample is measured by using time-resolved ICP-MS. The extent of broadening due to high concentrations of $\mathrm{Pb}$ in the sample is related inversely to the analyte mass. For the lightest analyte investigated, $\mathrm{Li}^{+}$, the relative width of the time-resolved analyte peak increases and then shows a dip in the center as the $\mathrm{Pb}$ concentration is increased to 500 and then 1500 $\mu \mathrm{g} / \mathrm{mL}$. The initial results of experiments that investigated chemical matrix effects as a function of concomitant species concentration, analyte mass, and sampling location in ICP-MS are consistent with space-charge effects. (J Am Soc Mass Spectrom 1996, 7, 362-367)
\end{abstract}

I nductively coupled plasma mass spectrometry (ICP-MS) is used widely for inorganic analysis, in 1 part, because the inductively coupled plasma (ICP) provides high atomization and ionization efficiency [1-3]. Detection limits for many elements are in the low part per trillion range. However, several problems that can degrade analysis accuracy remain [1-4]; they include spectral overlaps, particularly those due to molecular ions, and chemical matrix effects.

Typically, high concentrations of elements that are efficiently ionized in the ICP (most elements) suppress analyte ion signals [4-8]. The magnitude of the effect is generally more severe as the mass of the matrix ion increases or the mass of the analyte ion decreases.

It is now clear that there are two locations where ICP-MS chemical matrix effects originate: in the ICP itself and in the transport of ions from the plasma to the mass spectrometry detector. Laser-induced fluorescence measurements made in the ICP $[9,10]$ show that the number of analyte ions is generally depressed in the presence of high concentrations of efficiently ionized elements.

Processes in the ICP itself do not account for the mass dependence of the ICP-MS matrix effects. Both theoretical calculations [11] and experimental laser induced fluorescence measurements [11] show that the

Address reprint requests to Dr. John W. Olesik, Department of Geological Sciences, Laboratory for Plasma Spectrochemistry, Laser Spectroscopy and Mass Spectrometry, Ohio State University, 26 Mendenhall Laboratories, 125 S. Oval Mall, Columbus, OH 43210. chemical matrix effects that originate in the ICP itself are not mass dependent. An earlier claim that mass dependent effects could originate in the ICP itself [12] was shown to be mistaken [11] and authors of a recent review article [4] incorrectly reported the conclusions of the publication that clearly refuted the claim.

Space-charge effects that result in a mass-dependent decrease in the transport efficiency of ions from the ICP to the mass spectrometry detector have been postulated as a cause of ICP-MS chemical matrix effects $[13,14]$. The ion current measured at the entrance of the mass spectrometer was found to be far lower than that estimated from gas dynamic theory [13]. Gillson et al. [15] described experimental data that were consistent with a theoretical description of ICPMS chemical matrix effects based on space-charge repulsion. Tanner [16] has developed an iterative procedure for the calculation of space charge effects. Although the simulation operates at beam currents that are up to an order of magnitude lower than experimentally measured currents, it predicts mass dependent chemical matrix effects that are similar to those observed experimentally. Reductions in mass dependent ICP-MS chemical matrix effects by use of a high extraction potential [17] or a three aperture interface $[18,19]$ have been reported.

Direct experimental proof of the role of spacecharge effects in ICP-MS has been sought by a number of workers who have used targets in an attempt to collect ions and then measure element dependent broadening of the positive ion beam [20-23]. This approach suffers from potential difficulties in order to 
properly interpret the data and quantitatively relate the results to space-charge effects. Deposition of neutral species may be difficult to distinguish from ion deposition. The chemistry of the deposition process could be highly element dependent. Spatially dependent sputtering of deposited materials could affect the observed distribution of deposited elements. If space-charge repulsion results in loss of ions before the target, changes in beam diameter and mass dependent ion distribution downstream may be second order effects. Tanner and Houk [24] have recently suggested that the ion beam width at the entrance of the mass spectrometer should change little, if any, due to concomitant species.

If ions were introduced as a narrow, well defined pulse, broadening of the ion cloud in a direction along the ion beam axis due to space-charge effects could be detected by using time-resolved mass spectrometry. Broadening that occurred anywhere from the time the ions pass through the sampling orifice to the mass spectrometer detector would be observed. Of course, this approach is not without potential difficulties. If changes in the ion cloud diameter in the ICP itself occurred, it would be difficult to distinguish these from changes in the ion cloud size that occurred after ions passed through the sampling orifice. Implications of space-charge in a direction perpendicular to the ion beam, which would affect continuous ICP-MS signals, must be inferred from the measurements of ion cloud broadening in a direction along the ion beam. Previously, it has been shown that ion flight times from the sampling orifice to the mass spectrometry detector are mass dependent [24b]. This could also complicate interpretation because the analyte and matrix ions could become physically separated from each other at some point.

Previously, Dziewatkoski and Olesik [24b] described time-resolved ICP-MS measurements of individual ion clouds by using a monodisperse dried microparticulate injector (MDMI) sample introduction device developed by French et al. [25]. The MDMI allows individual, monodisperse drops of solution to be reproducibly transported into the ICP. Because the sample drops produced by the MDMI are monodisperse, each should begin to vaporize at the same location in the plasma. Similarly, initial production of ions should be at the same location in the plasma for each drop.

Ion clouds produced in the ICP from single drops of sample solution can be detected simultaneously by optical emission spectrometry (OES) and mass spectrometry. When the concentration of dissolved solids is low, the time-resolved ICP-OES peak width detected within $1 \mathrm{~mm}$ of the ICP-MS sampling orifice is similar to or narrower than the corresponding ICP-MS peak width [24b]. The widths of the ICP-OES or ICP-MS peaks as a function of distance from the initial observation of emission were consistent with diffusion in the ICP. A mass-dependent delay time between the
OES and mass spectrometry signals produced from a particular drop of sample was observed [24b].

In this article, time-resolved ICP-MS and ICP-OES signals were acquired simultaneously to assess the effect of high concentrations of lead on analyte ion peak widths. Initial results by using time-resolved ICP-MS measurements to investigate space-charge effects during the transport of analyte ions from the ICP to the mass spectrometry detector are described.

\section{Experimental}

The ICP-MS instrument we used was based on a laboratory modified Extranuclear (now Extrel ANS, Madison, WI) EMBA quadrupole mass spectrometer and a $40-\mathrm{MHz}$ plasma generator with center-grounded load coil, as described previously [24b, 26]. A monodisperse dried microparticulate injector (MDMI) [25, 27], oriented horizontally, was used to reproducibly introduce individual, monodisperse drops of sample into the ICP. Optical emission was collected by using a fiber optic and 0.2-m monochromator [24b]. Emission was collected along a line of sight through the plasma, across the analyte channel (perpendicular to the plasma axis), and approximately $100 \mu \mathrm{m}$ wide along the plasma axis. The optical collection volume was approximately $1 \mathrm{~mm}$ upstream of the sampling orifice for most measurements. Time-resolved ICP-MS and ICPOES signals were simultaneously collected [24b] by using high speed current amplifiers and a digital oscilloscope at a rate of $500 \mathrm{kHz}$. Experimental parameters were identical to those described previously [24b].

Full width at half maximum values of peaks in time-resolved ICP-MS and ICP-OES signals were determined by using Peak Fit (Jandel, San Rafael, CA) software. The time-resolved waveforms shown in the figures herein are the result of signal averaging of six or more peaks. The ICP-OES waveforms were manually shifted in time to best match the peaks (centers) before signal averaging. The corresponding ICP-MS waveforms each were shifted by the same amount of time as the simultaneously detected OES waveform before signal averaging.

\section{Results and Discussion}

Lithium and lead were chosen as the initial analyte and matrix species to investigate, respectively, because both are ionized efficiently in the ICP and lithium is a light element whereas lead is heavy. This choice should produce the most severe space-charge effect on the analyte signal. To minimize the possibility that a change in the time required for analyte vaporization could result in a broadening of the ICP-MS signals due to an earlier production of ions in the ICP (and therefore a longer time for diffusion to occur before the ions reach the mass spectrometer sampling orifice), the plasma was moved relative to the mass spectrometer 
sampling orifice as necessary. The distance between the location of initial detectable $\mathrm{Li}, \mathrm{Sr}$ ion, or $\mathrm{Mg}$ ion emission (depending on the sample) and the sampling orifice was made coincident, independent of the concentration of lead, and typically required movement of the plasma by $2 \mathrm{~mm}$ or less.

Time-resolved ${ }^{7} \mathrm{Li}^{+}$ICP-MS signals acquired from samples that contained no $\mathrm{Pb}$ and 500 and $1500-\mu \mathrm{g} / \mathrm{mL}$ $\mathrm{Pb}$ are shown in Figure 1. Because drop to drop signal variations were large (up to $50 \%$ ), the. signals were normalized. The ${ }^{7} \mathrm{Li}^{+}$peak width increased as the concentration of $\mathrm{Pb}$ was increased. This increase suggests that the presence of high concentrations of $\mathrm{Pb}^{+}$ in the ion cloud leads to space-charge repulsion of the $\mathrm{Li}^{+}$. Inferences regarding the relative delay times for the $\mathrm{Li}^{+}$ICP-MS cannot be made from this set of data.

If the time-resolved peak broadening observed in Figure 1 was due to space-charge repulsion, the effect should be less severe for heavier analyte ions. Figure 2 shows the time-resolved ${ }^{7} \mathrm{Li}^{+},{ }^{24} \mathrm{Mg}^{+}$, and ${ }^{63} \mathrm{Cu}^{+} \mathrm{ICP}-$ MS signals in the absence and presence of $1500-\mu \mathrm{g} / \mathrm{mL}$ $\mathrm{Pb}$. The severity of the peak width broadening in the presence of $\mathrm{Pb}$ decreases with increasing mass of the analyte ion, as expected if the broadening is due to space-charge repulsion.

In addition to the broadening, the initial arrival of analyte ions at the mass spectrometry detector appears to be earlier when high concentrations of $\mathrm{Pb}^{+}$were present in the sample. (The time scales for the data in the presence and absence of $\mathrm{Pb}$ were synchronized by using the $\mathrm{Mg}$ ion emission signals, that were collected simultaneously with the ICP-MS signals, as a reference.) The earlier initial arrival of analyte ions can be explained with two different, but consistent, descriptions. The kinetic energy of ions on the front side of the

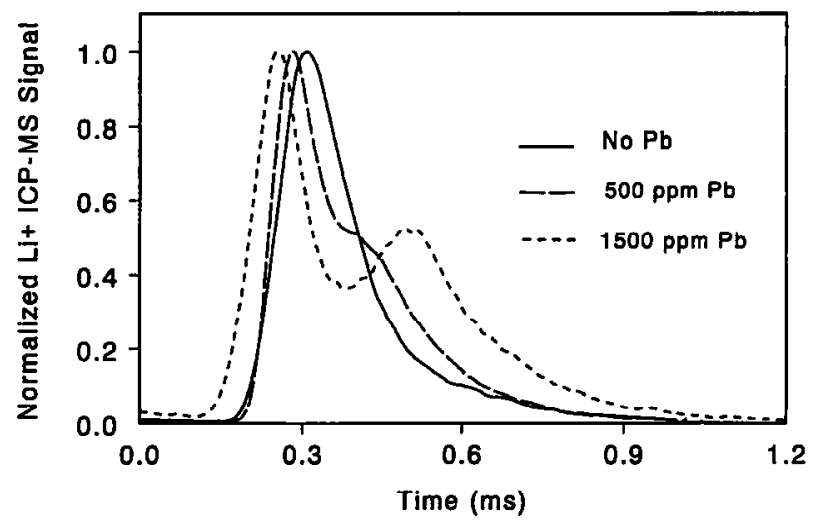

Figure 1. Time-resolved ${ }^{7} \mathrm{Li}^{+}$ICP-MS signals in the presence of $0-, 500-$, and $1500-\mu \mathrm{g} / \mathrm{mL} \mathrm{Pb}$. The $\mathrm{Li}$ concentration was 100 $\mu \mathrm{g} / \mathrm{mL}$. The time scales for each of the three waveforms are not synchronized to each other. Seven individual waveforms, each produced from a single drop of sample, were manually shifted (in time) for consistent fit and then averaged. The averaged waveforms are displayed to allow easy comparison of peak widths and shapes. The sampling orifice was $7 \mathrm{~mm}$ from initial detectable emission.
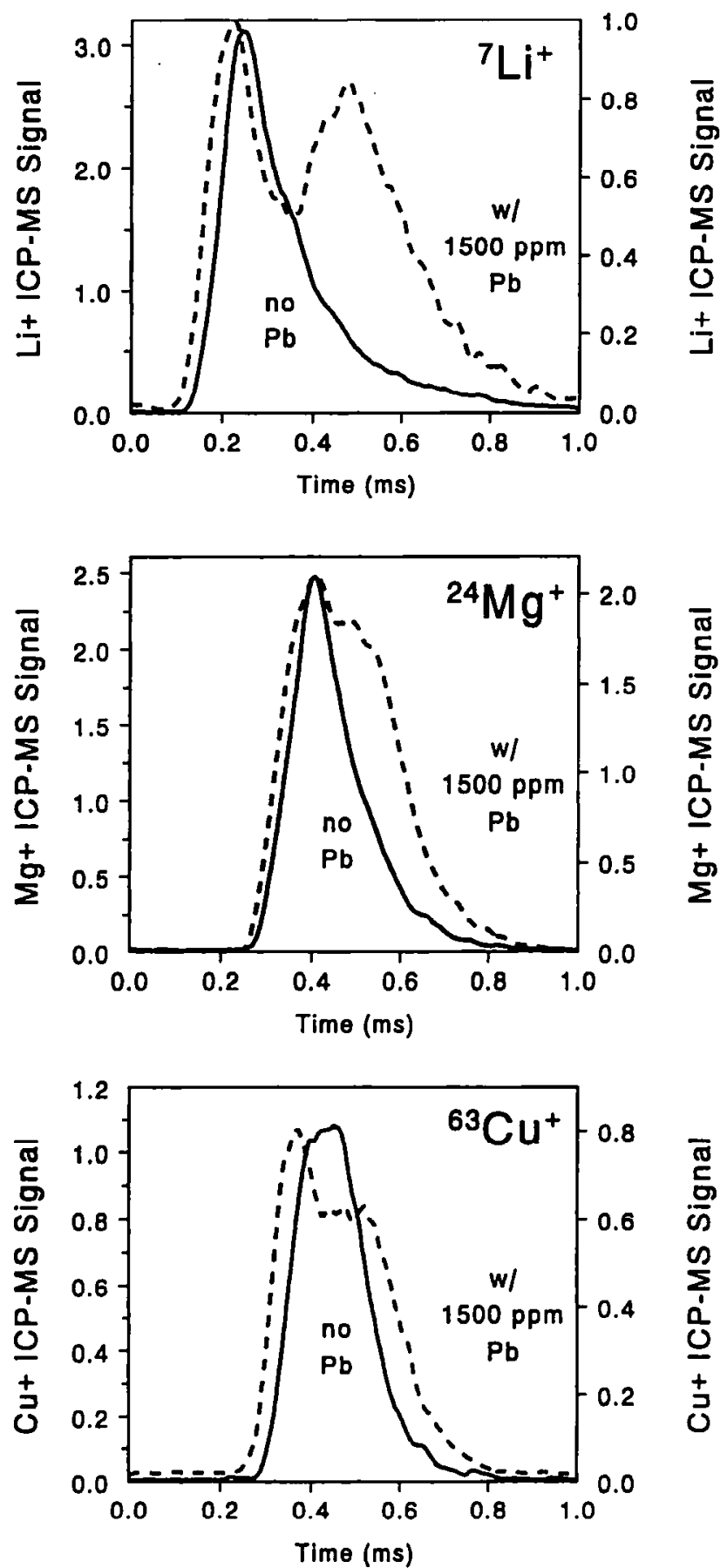

Figure 2. Time-resolved (a) ${ }^{7} \mathrm{Li}^{+}$, (b) ${ }^{24} \mathrm{Mg}^{+}$, and (c) ${ }^{63} \mathrm{Cu}^{+}$ ICP-MS with 0 - or $1500-\mu \mathrm{g} / \mathrm{mL} \mathrm{Pb}$. The concentrations of $\mathrm{Li}, \mathrm{Mg}$, and $\mathrm{Cu}$ were 100,100 , and $500 \mu \mathrm{g} / \mathrm{mL}$, respectively. Seven individual waveforms, each produced from a single drop of sample, were manually shifted (in time, by using the $\mathrm{Mg}$ ion OES signal as a reference) for consistent fit and then averaged. The time scales for each waveform were synchronized to each other by using $\mathrm{Mg}$ ion emission waveforms simultaneously acquired with each ICP-MS waveform. The sampling orifice was $3 \mathrm{~mm}$ from initial detectable emission. The right $y$-axis is for signals detected in the presence of $\mathrm{Pb}$ (dashed line). 
ion cloud will increase due to space-charge repulsion. Ions on the back side of the ion cloud should have lower kinetic energy due to repulsion from ions closer to the center of the ion cloud.

Alternatively, the space-charge effect can be thought of as an increase in the size of the ion cloud. A high concentration of heavy ions in the center of the ion cloud will result in a repulsion of analyte ions that will produce a net movement of analyte ions in all directions outward from the center of the ion cloud. As a result, the analyte ion cloud becomes larger. If the concentration of heavy ions in the center of the ion cloud is high enough, it is possible that enough analyte ions will be repelled outward from the center so that the highest concentration of analyte ions is outside of the radial center of the ion cloud. This was observed only for the lightest analyte ion $\left(\mathrm{Li}^{+}\right)$in the presence of the highest concentration of $\mathrm{Pb}$ used $(1500 \mathrm{ppm})$. Because the rate of diffusion of $\mathrm{Li}^{+}$in the ICP is larger than that of $\mathrm{Pb}^{+}$, the $\mathrm{Li}^{+}$will be distributed over a broader volume than the $\mathrm{Pb}$ ions when the $\mathrm{Li}$ and $\mathrm{Pb}$ ions leave the plasma [DO]. This situation could lead to more severe space-charge effects than if the $\mathrm{Li}$ and $\mathrm{Pb}$ ions were contained within volumes with equal radii.

The presence of $\mathrm{Pb}$ in the sample consistently leads to an earlier initial rise in the time-resolved analyte ICP-MS signals. However, the magnitude of the apparent shift in the initial arrival time of ions (about $50 \mu \mathrm{s}$ ) when $\mathrm{Pb}$ is present in the sample is surprisingly large in the case of $\mathrm{Li}$ ions. Based on a comparison of the time between the peak emission intensity and peak ICP-MS signal intensity, the flight times of $\mathrm{Li}$ ions from the ICP to the mass spectrometry detector are expected [DO] to be less than $20 \mu \mathrm{s}$, which suggests that either there was slight broadening of the $\mathrm{Li}$ ion cloud in the ICP itself or there is uncertainty in the time scale of at least $30 \mu \mathrm{s}$.

To determine if the observed ICP-MS peak width broadening occurred in the ICP or only after ions were sample from the ICP, optical emission signals also were measured in the presence and absence of 1500$\mu \mathrm{g} / \mathrm{mL} \mathrm{Pb}$. As shown in Figure 3, the time-resolved $\mathrm{Mg}$ ion OES peak width was affected little by the presence of high concentrations of $\mathrm{Pb}$. However, for the experiment with $\mathrm{Li}$ and $\mathrm{Pb}$ (Figure $2 \mathrm{a}$ ), there is a slight broadening of the $\mathrm{Mg}$ ion OES signal (Figure 3a) that may explain part of the earlier arrival of $\mathrm{Li}$ ions. Figure $3 \mathrm{~b}$ shows the time-resolved OES peaks with and without $\mathrm{Pb}$ in the sample acquired simultaneously with the mass spectrometry data shown in Figure $2 b$.

Although the data shown in Figure 3 strongly suggest that the ion cloud with or without $\mathrm{Pb}$ in the sample was similar in size, the data must be viewed with caution. Emission intensities depend on both the number of analyte ions in the observation volume and the fraction excited. Therefore, if the fraction of analyte ions that are excited changes as a function of position
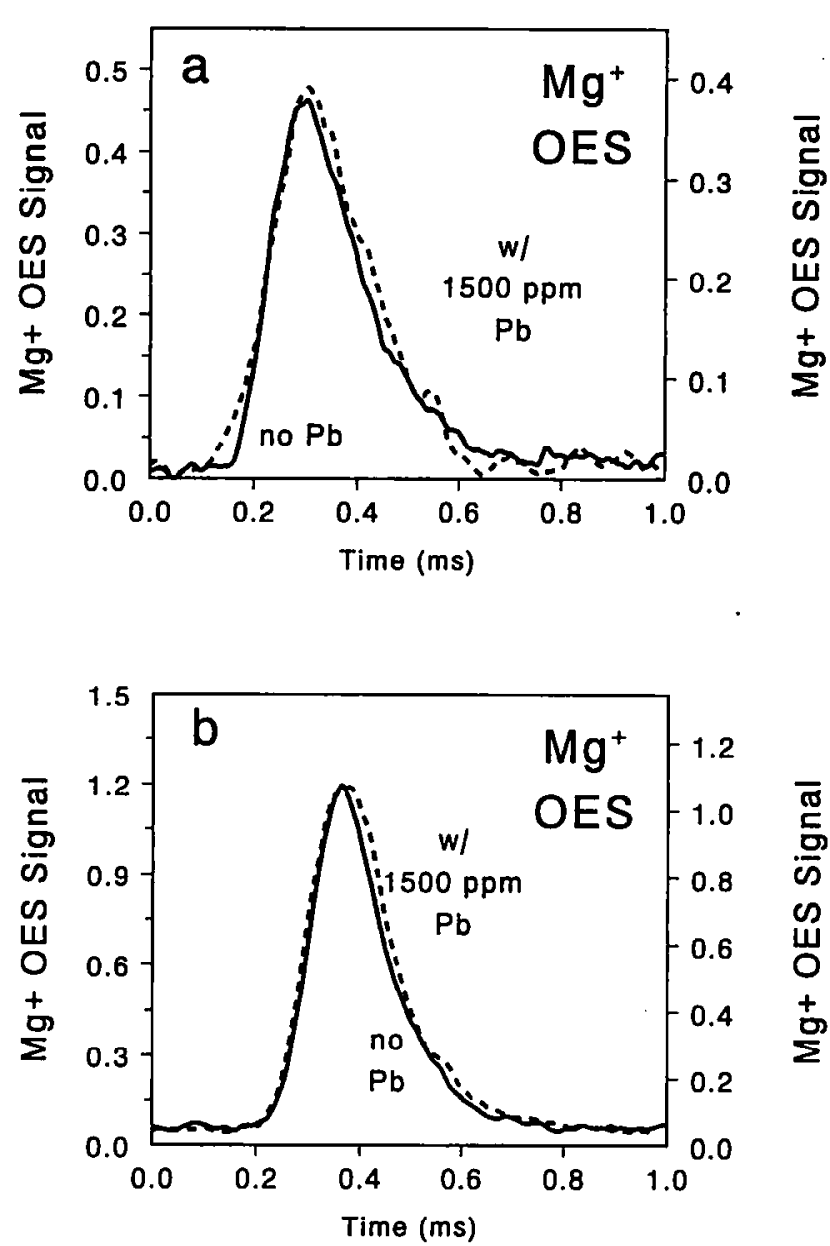

Figure 3. Effect of $\mathrm{Pb}$ on time-resolved $\mathrm{Mg}$ ion optical emission signals with 0 - and $1500 \mu \mathrm{g} / \mathrm{mL} \mathrm{Pb}$. The $\mathrm{Mg}$ concentration was $400 \mu \mathrm{g} / \mathrm{mL}$. Emission signals were acquired (a) simultaneously with the ICP-MS signals shown in 2a and (b) simultaneously with the ICP-MS signals shown in Figure $2 b$. Seven individual waveforms, each produced from a single drop of sample, were manually shifted (in time, by using the $\mathrm{Mg}$ ion OES signal as a reference) for consistent fit and then averaged. The right $y$-axis is for signals detected in presence of $\mathrm{Pb}$ (dashed line).

within the ion cloud, the time-resolved ICP-OES signal is not related directly to the time-resolved ion concentration. In some cases, OES peak widths were slightly wider in the presence of $\mathrm{Pb}$. However, the broadening was far less severe for the OES peaks than for the ICP-MS signals. Furthermore, the ICP-MS peak widths always were broadened, relative to the ICP-OES peaks, when a high concentration of $\mathrm{Pb}$ was present in the sample.

The ion concentration should be highest during the time the desolvated analyte particle is vaporizing, or shortly thereafter, depending on ionization kinetics and local temperatures. Once particle vaporization is complete, diffusion should lead to a continual decrease in the analyte and matrix ion concentrations. Therefore, the severity of the space-charge effect should decrease as the ICP-MS sampling orifice is moved farther away from the location of maximum ion concentration in the ICP. 

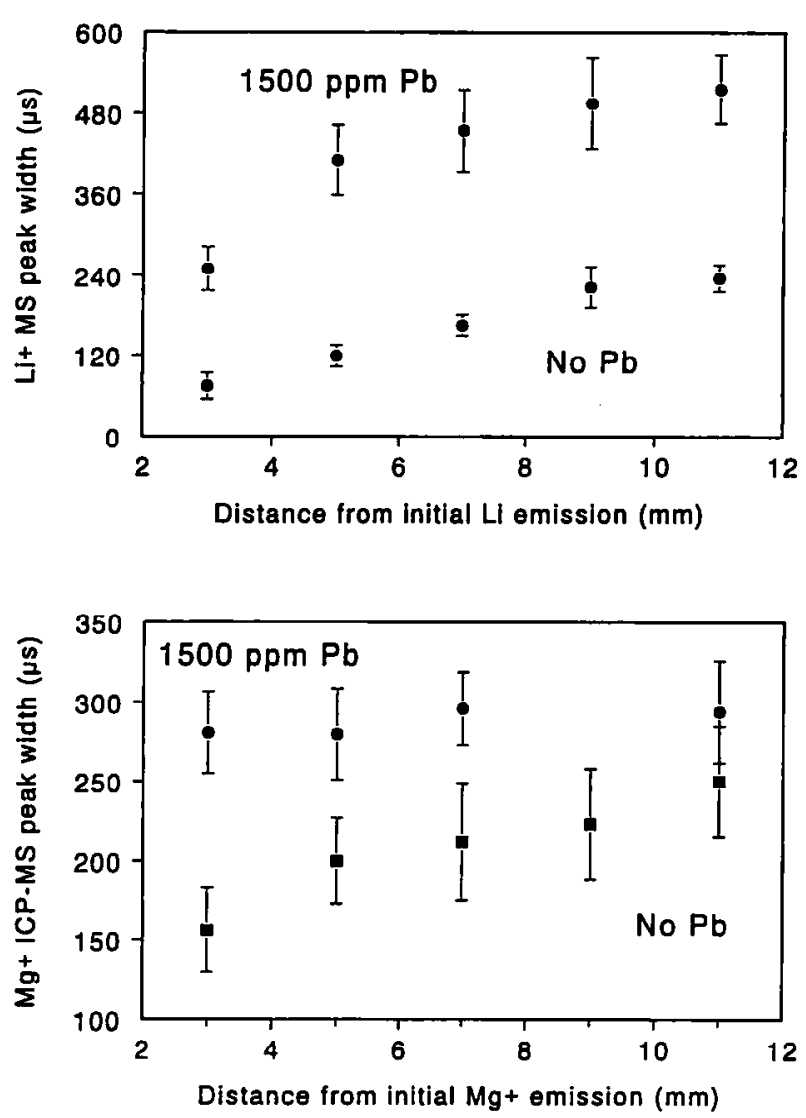

Figure 4. Full width at half maximum (FWHM) of time-resolved peaks as a function of distance from initial detectable emission. (a) ${ }^{7} \mathrm{Li}^{+}$ICP-MS peak widths. The concentration of $\mathrm{Li}$ was $100 \mu \mathrm{g} / \mathrm{mL}$. (b) ${ }^{24} \mathrm{Mg}^{+}$ICP-MS peak widths. The $\mathrm{Mg}$ concentration was $400 \mu \mathrm{g} / \mathrm{mL}$. Error bars indicate \pm 1 standard deviation of FWHM values from 15 or 16 waveforms, each produced from a single drop of sample.

Figure 4 shows the full width at half maximum of the time-resolved ${ }^{7} \mathrm{Li}^{+}$and ${ }^{24} \mathrm{Mg}^{+}$ICP-MS signals in the absence and presence of $1500-\mu \mathrm{g} / \mathrm{mL} \mathrm{Pb}$ in the sample. When no $\mathrm{Pb}$ is present, the time-resolved ICP-MS peak widths increase with increasing distance from the location of initial detectable emission, consistent with diffusion. The extent of broadening due to the presence of $\mathrm{Pb}$, indicated by the relative difference between the peak width when $\mathrm{Pb}$ is absent and the peak width when $\mathrm{Pb}$ is present, decreases as the sampling orifice is moved away from the location of initial detectable emission. For example, the ${ }^{7} \mathrm{Li}^{+}$peak width increased 230,176, and $118 \%$ due to the presence of $1500-\mu \mathrm{g} / \mathrm{mL} \mathrm{Pb}$ when the sampling orifice was 3,7 , and $11 \mathrm{~mm}$, respectively, downstream of the first detectable $\mathrm{Li}$ atom emission. The increase in ${ }^{24} \mathrm{Mg}^{+}$peak width due to the presence of $\mathrm{Pb}$ was 88,40 , and $18 \%$ when the sampling orifice was 3,7 , and $11 \mathrm{~mm}$, respectively, downstream of the first detectable $\mathrm{Mg}^{+}$ emission intensity. This behavior is again consistent with space-charge effects after ions are sampled from the ICP. The magnitude of the space-charge-induced ion cloud broadening should decrease as the matrix ion concentration decreases due to diffusion in the ICP.

\section{Conclusions}

Time-resolved ICP-MS measurements of individual ion clouds, each produced from a single monodisperse drop of sample, provide a unique means to directly observe ion transport processes in plasma source mass spectrometry. The initial results of the investigation of the effect of high concentrations of efficiently ionized elements in the sample are consistent with space-charge repulsion of ions after the ions are sampled from the ICP. The results show that the mass dependent portion of chemical matrix effects observed in ICP-MS originate during the transport of ions from the plasma to the mass spectrometry detector.

Further improvements in the reproducibility of monodisperse drop production and transport into the ICP would allow more quantitative measurement of the effect of high concentrations of efficiently ionized elements on both the number of ions transported from the ICP to the mass spectrometry detector (determined from the area under the time-resolved ICP-MS signal peaks) and space-charge-induced changes in the ion kinetic energies of ions in the front and back of the ion cloud. Our experience with the MDMI shows that much higher reproducibility can be obtained when the MDMI is oriented vertically [27] rather than horizontally [DO]. Therefore, we are rebuilding the ICP-MS instrument to operate vertically. Then more detailed, time-resolved measurements will be made with a wide variety of analyte and matrix species in combination with optical emission and laser-induced fluorescence measurements to further elucidate the processes responsible for chemical matrix effects in ICP-MS.

\section{Acknowledgments}

This research was supported by the National Science Foundation (CHE-9217170) and the Perkin-Elmer Corporation. Barry French, Ben Etkin, and Ray Jong (University of Toronto Institute for Aerospace Science) are thanked for developing and providing the MDMI.

\section{References}

1. Montaser, G.; Golightly, G. W., Eds. Inductively Coupled Plasmas in Analytical Atomic Spectrometry, 2nd ed.; VCH Publishers: New York, 1992.

2. Jarvis, K. E.; Gray, A. L.; Houk, R. S., Eds. Handbook of Inductively Coupled Plasma Mass Spectrometry, Chapman and Hall: New York, 1992.

3. Olesik, J. W. Anal. Chem. 1991, 63, 12A-21A.

4. Evans, E. H.; Giglio, J. J. J. Anal. At. Spectrom, 1993, 8, 1-18.

5. Tan, S. H.; Horlick, G. J. Anal. At. Spectrom. 1987, 2, 745.

6. Olivares, J. A.; Houk, R. S. Anal. Chem. 1986, 58, 20.

7. Beauchemin, D.; McLaren, J. W.; Berman, S. S. Spectrochim. Acta Part B, 1987, 42, 467.

8. Crain, J. S.; Houk, R. S.; Smith, F. G. Spectrochim. Acta Part B 1988, 43, 1355-1364.

9. Gillson, G.; Horlick, G. Spectrochim. Acta Part B 1986, 41, 619.

10. Olesik, J. W.; Williamsen, E. J. Appl. Spectrosc. 1989, 4.3, 1223. 
11. Hobbs, S. E.; Olesik, J. W. Appl. Spectrosc. 1991, 45, 1395-1407.

12. Gregoire, D. C. Spectrochim. Acta Part B 1987, 42, 895.

13. Olivares, J. A.; Houk, R. S. Anal. Chem. 1985, 57, 2674.

14. Tan, S. H.; Horlick, G. J. Anal. At. Spectrom. 1987, 2, 745.

15. Gillson, G. R.; Douglas, D. J.; Fulford, J. E.; Halligan, K. W.; Tanner, S. D. Anal. Chem. 1988, 60, 1472.

16 Tanner, S. D. Spectrochim. Acta Part B 1992, 47, 209.

17. Turner, P. In Applications of Plasma Source Mass Spectrometry, Vol. II; Holland, G.; Eaton, A. N., Eds.; Royal Society of Chemistry: Cambridge, 1993.

18. Tanner, S. D.; Douglas, D. J.; French, J. B. Appl. Spectrosc. 1994, 48, 1373.

19. Tanner, S. D.; Cousins, L. M.; Douglas, D. J. Appl. Spectrosc. 1994, 48, 1367.

20. Farnsworth, P. B.; Chen, Y.; Wu, M.; Sin, J.; Lee, M. L.
Presented at 1994 Pittsburgh Conference on Analytical Chemistry and Applied Spectroscopy; paper 007.

21. Farnsworth, P. B.; Chen, Y.; Wu, M. Presented at 1994 Federation of Analytical Chemistry and Spectroscopy Societies Meeting; paper 773.

22. Chen, X. C.; Houk, R. S. Spectrochim. Acta Part B 1996, in press.

23. Li, G.; Duan, Y.; Hiefte, G. M. J. Mass Spectrom. 1995, 30, 341-848.

24. Tanner, S. D.; Houk, R. S. Presented at 1996 Winter Conference on Plasma Spectrochemistry.

24b. Dziewatkoski, M. P.; Daniels, L. B.; Olesik, J. W. Anal. Chem. 1996,68 , in press.

25. French, J. B.; Etkin, B.; Jong. R. Anal. Chem. 1994, 66, 685-691.

27. Hobbs, S. E.; Olesik, J. W. Anal. Chem. 1992, 64, 275-283.

28. Olesik, J. W.; Hobbs, S. E. Anal. Chem. 1994, 66, 3371-3378. 